\title{
Argumentation Frameworks - A Brief Review
}

\author{
https://doi.org/10.3991/ijoe.v18i02.28023
}

\author{
Ahmed T. Sadiq $\left.{ }^{1}{ }^{\varpi}\right)$, Hasanen S. Abdulah ${ }^{1}$, Adnan Taher Kareem ${ }^{2}$ \\ ${ }^{1}$ Computer Sciences Department, University of Technology, Baghdad, Iraq \\ ${ }^{2}$ Iraqi Ministry of Communications, Baghdad, Iraq \\ cs.19.27@grad.uotechnology.edu.iq
}

\begin{abstract}
The main aim of this article is to provide a short review of the most important argumentation frameworks (AFs) systems being used. This paper presents the overall thought of unique argumentation, featuring the work way of these theoretical systems in the argumentation interaction and surveys the first Dung structures. It introduces how these systems give acceptable arguments by focused on the argumentation frameworks structures and how to deal with the arguments and the basic rules to give the result. Finally, it surveys the idea of theoretical rationalistic structures, quite possibly the broadest frameworks for dynamic argumentation, and gives a short description of several argumentation frameworks that are more famous.
\end{abstract}

Keywords-argumentation frameworks, attack, support

\section{$1 \quad$ Introduction}

The argumentation is a significant focal point in Artificial Intelligence (AI), especially in recent years. It has become a very important component in this field $[1,2,3]$. It is associated with and helpful to other AI subfields, specifically information portrayal, nonmonotonic thinking, and multi-specialist frameworks. It has been effectively applied to lawful thinking, which utilizes argumentation standards to plan legitimate cases as arguments [3]. It has demonstrated importance in helping to solve attacks between various arguments and to give results [4], furthermore with regard to discourse and influence [5,6]. Inside argumentation we can recognize the significance to lines of development within the argumentation frameworks focused on two issues:

- Logic-based approached: considers the sensible design of arguments and characterizes thoughts like attack, undercut, solidness and so forth as far as coherent properties of picked argument structures [2,7].

- Abstract approaches: think about arguments as nuclear things, the relationship between above issues. Subsequently, it is accepted that the arguments and the necessary relation that occurs have effectively been developed, ordinarily from essential information that is given from the system. Then the argumentation framework is evaluated on a theoretical basis, yielding potentially elective to abstract arrangements that are arguments which might be altogether acknowledged [8]. 
This paper gives an outline of the most well-known argumentation frameworks. The two issues that are mentioned above address and overcome any barrier between the displaying dialects and argumentation frameworks:

- The first is meta-argumentation. It permits us to remain in the grounded setting of Dung. Be that as it may, it comes at the expense of assistant arguments which are needed to address relations other than attack [9].

- The second spotlights broadening argumentation frameworks by furnishing them these ideas that are more expensive to show than previously mentioned circumstances, for example, inclinations or backing relations [10, 11].

The argumentation frameworks that are used in various fields of application such as decision making [12], to build expert systems [12], digital transformation of institutions [13], also have many uses related to artificial intelligence [14, 15], with application work with conflict $[15,16]$ the argumentation also can support game theory and take advantage between each other $[10,17,18]$ because argumentation also works as a game. Dialogue $[18,19]$ argumentation frameworks are used to solve different types of problems such as stable marriage problems [20, 21]. The argumentation methods can be found in a few master frameworks from such various zones as medication $[22,23]$ or electronic government [24].

This paper is structured as follows. It start with an overview of the argumentation framework, a theoretical background to the frame work and how they make the process; it also focuses on and highlights a number of frameworks by presenting the elements used to build these frameworks, by providing background on frameworks and the processing operations that are introduced by the argumentations systems and provides an overview of how these systems are work, finally giving a summary including the main idea of each one.

\section{$2 \quad$ Argumentation process}

Argumentation often starts with three essential stages:

- The first stage is exchange of arguments: a set of argument generally alludes to the ideas of clarification, support, and may confirmation to the main argument. The arguments plan to legitimize convictions or choices. They can appear as a part of sentence or speech. By putting forward an argument, a person tries to convince the recipient of the validity of the case for which he is discussing, or that it is an affirmation of a specific case. Officially, arguments revolve around clear conceptual language, and they can learn specific types of arguments and accumulate events, learn, and build arguments. Besides, arguments are shaped by an information base that cannot be thought about autonomously. In fact, most of the arguments are in collaboration: in often there are to main issues to each argument support or attack, argument may insert to support other argument [25, 26, 27].

- The second stage is valuation of interacting arguments: imposed or weakened by other arguments the main idea is to give weight to each argument, and the accepta- 
bility of that argument is determined by relying on the weights of the other arguments. This often leads to the settlement of arguments in a system of weighted arguments [28, 29].

- The third stage is selecting the most acceptable arguments: this stage is very important to characterize the situation with arguments based on every one of the manners by which they communicate to settle the outcome of the controversy. As a yield of the argumentation framework, the best arguments should be distinguished. Based on the arguments put forward, they build goals and beliefs, legitimize accepted arguments, and adopt them as a proactive result of decision-making [30] or any other goal to the argumentation system. Regularly, worthiness is aggregate as in sets of arguments are demonstrated satisfactory if they fulfill specific properties. Various types of properties characterize distinctive semantics for worthiness [21].

\section{Argumentation frameworks (AF)}

Dung gives argumentation dependent on a thought of argumentation system characterized as two couples. The first is a set of argumenta the second is relation between them. Different structures exploit from this system by adding new components or adding conditions to improve it or enhancement it. These activities create another argumentation system; this paper gives featuring some of them [15]. (Table 1).

Table 1. Summary of the argumentation frameworks

\begin{tabular}{|c|c|c|c|c|}
\hline No. & framework & framework elements & Main idea & Application area \\
\hline 1 & $\begin{array}{l}\text { Dung's Argumenta- } \\
\text { tion Frameworks } \\
\text { (AF) }\end{array}$ & $\begin{array}{l}\text { (arg, att) where - } \\
\text { represents a set of ar- } \\
\text { guments, } \\
\text { - The second one is (att): } \\
\text { is represents a binary } \\
\text { relation on arg. }\end{array}$ & $\begin{array}{l}\text { The main idea of this } \\
\text { framework is that repre- } \\
\text { sents different types of } \\
\text { nonmonotonic approaches } \\
\text { in a uniform setting and } \\
\text { determine the arguments if } \\
\text { it acceptable or not. }\end{array}$ & $\begin{array}{l}\text { - Artificial intelli- } \\
\text { gence. } \\
\text { - Decision making. } \\
\text { - Applications with } \\
\text { conflict. }\end{array}$ \\
\hline 2 & $\begin{array}{l}\text { Preferences based } \\
\text { argumentation } \\
\text { frameworks (PAFs) }\end{array}$ & $\begin{array}{l}(\mathrm{X}, \mathrm{Y}, \geq) \text { where - } \\
-\mathrm{X} \text { represents the set of } \\
\text { arguments. } \\
\text { - } \mathrm{Y} \text { represents the binary } \\
\text { relation addressing the } \\
\text { loss connection where } \\
\text { arguments } \mathrm{Y} \subseteq \mathrm{X} \times \mathrm{X} \text {. } \\
\text { - } \text { Pref is a (partial or all) } \\
\text { preordering on } \mathrm{X} \times \mathrm{X} \text {. }\end{array}$ & $\begin{array}{l}\text { The main idea of this } \\
\text { framework it extends the } \\
\text { Dung's framework to be } \\
\text { three elements this element } \\
\text { represents the condition to } \\
\text { Determines the acceptabil- } \\
\text { ity of the argument. }\end{array}$ & $\begin{array}{l}\text { - Artificial intelli- } \\
\text { gence. } \\
\text { - Decision making. } \\
\text { - Applications with - } \\
\text { conflict. } \\
\text { - Expert systems. }\end{array}$ \\
\hline 3 & $\begin{array}{l}\text { Value based argu- } \\
\text { mentation frame- } \\
\text { works (VAFs) }\end{array}$ & $\begin{array}{l}\text { (Arguments, attacks, } \\
\text { values, Val, P) where - } \\
\text { - AR: represents the finite } \\
\text { tuple that include argu- } \\
\text { ments. } \\
\text { - Attacks: represents the } \\
\text { non-reflexive binary } \\
\text { relation on tuple AR. } \\
\text { - values: represents the } \\
\text { nonempty tuple of val- }\end{array}$ & $\begin{array}{l}\text { The main idea to the VAF } \\
\text { is that it can be provide a } \\
\text { rational basis for the } \\
\text { acceptance or rejection of } \\
\text { arguments by making } \\
\text { comparison between the } \\
\text { attacked argument and } \\
\text { supported arguments and } \\
\text { choose between them. }\end{array}$ & $\begin{array}{l}\text { - Artificial intelli- } \\
\text { gence. } \\
\text { - Decision making. } \\
\text { - Applications with } \\
\text { conflict. } \\
\text { - Expert systems. }\end{array}$ \\
\hline
\end{tabular}




\begin{tabular}{|c|c|c|c|c|}
\hline & & $\begin{array}{l}\text { ues. } \\
\text { Val: represents the } \\
\text { function which maps } \\
\text { from elements of tuple } \\
\text { AR to elements of tuple } \\
\text { values. } \\
\text { - P: represents the tuple of } \\
\text { possible audiences. }\end{array}$ & & \\
\hline 4 & $\begin{array}{l}\text { extended argumenta- } \\
\text { tion framework } \\
\text { (EAF) }\end{array}$ & $\begin{array}{l}\text { (Arguments, } \mathrm{X}, \mathrm{Y}) \text { where - } \\
\text { - arguments represent the } \\
\text { tuple of arguments. } \\
\text { - } \mathrm{X} \subseteq \text { arguments } \times \text { argu- } \\
\text { ments. } \\
\text { - } \mathrm{Y} \subseteq \text { arguments } \times \mathrm{X} \text {. }\end{array}$ & $\begin{array}{l}\text { The main idea for (EAF) is } \\
\text { that it not only attack other } \\
\text { arguments but also at the } \\
\text { same time allows the } \\
\text { argument to generate a } \\
\text { more advanced conflict } \\
\text { relation. }\end{array}$ & $\begin{array}{l}\text { - Artificial intelli- } \\
\text { gence. } \\
\text { - Decision making. } \\
\text { - Applications with } \\
\text { conflict. } \\
\text { - Expert systems. }\end{array}$ \\
\hline 5 & $\begin{array}{l}\text { bipolar argumenta- } \\
\text { tion framework } \\
\text { (BAF) }\end{array}$ & $\begin{array}{l}\text { (X, Ydef, Ysup) where - } \\
\text { - X: represent the tuple of } \\
\text { arguments. } \\
\text { - Ydef: represent the } \\
\text { binary relation Ydef on } \\
\text { tuple X that is represent } \\
\text { the defeat relation. } \\
\text { - Ysup: represent the } \\
\text { binary relation Rsup on } \\
\text { tuple X that is represent } \\
\text { the support relation. }\end{array}$ & $\begin{array}{l}\text { The main idea of the BAF } \\
\text { is that it gives to set of } \\
\text { relationship defeat relation } \\
\text { and support relation. }\end{array}$ & $\begin{array}{l}\text { - Artificial intelli- } \\
\text { gence. } \\
\text { - Decision making. } \\
\text { - Applications with } \\
\text { conflict. } \\
\text { - Expert systems. }\end{array}$ \\
\hline 6 & $\begin{array}{l}\text { abstract dialectical } \\
\text { frameworks (ADFs) }\end{array}$ & $\begin{array}{l}(\mathrm{X}, \mathrm{Y}, \mathrm{Z}) \text { where - } \\
\text { - } \mathrm{X} \text { : represent the tuple } \\
\text { statements (positions, } \\
\text { nodes). } \\
\text { - } \mathrm{Y} \text { : represented by } \mathrm{Y} \subseteq \\
\mathrm{X} \times \mathrm{X} \text { is a tuple of links. } \\
\text { - } \mathrm{Z} \text { : represented by } \mathrm{Z}= \\
\{\mathrm{Zx}\} \mathrm{x} \in \mathrm{X} \text { is a tuple of } \\
\text { total functions. }\end{array}$ & $\begin{array}{l}\text { The main idea is to estab- } \\
\text { lish a specific acceptance } \\
\text { condition for arguments } \\
\text { that allows for abstract } \\
\text { arguments as well as for } \\
\text { flexible and abstract rela- } \\
\text { tionships that thing occur } \\
\text { by adding this acceptance } \\
\text { condition. }\end{array}$ & $\begin{array}{l}\text { - Artificial intelli- } \\
\text { gence. } \\
\text { - Decision making. } \\
\text { - Applications with } \\
\text { conflict. } \\
\text { - Expert systems. }\end{array}$ \\
\hline 7 & $\begin{array}{l}\text { control argumenta- } \\
\text { tion frameworks } \\
\text { (CAFs) }\end{array}$ & $\begin{array}{l}(\mathrm{X}, \mathrm{Y}, \mathrm{Z}) \text { where - } \\
\text { - X: this element repre- } \\
\text { sents the fixed part in } \\
\text { the framework. } \\
\text { - Y: this element repre- } \\
\text { sents the uncertain part } \\
\text { in the framework. } \\
\text { - Z: this element repre- } \\
\text { sents the control part in } \\
\text { the framework. }\end{array}$ & $\begin{array}{l}\text { The main idea to the CAF } \\
\text { it provides dynamic model, } \\
\text { it can change over time } \\
\text { reflecting the dynamics of } \\
\text { the environment. }\end{array}$ & $\begin{array}{l}\text { - Artificial intelli- } \\
\text { gence. } \\
\text { - Decision making. } \\
\text { - Applications with } \\
\text { conflict. } \\
\text { - Expert systems. } \\
\text { - Continuous models. }\end{array}$ \\
\hline 8 & $\begin{array}{l}\text { Weighted argument } \\
\text { framework (WAF) }\end{array}$ & $\begin{array}{l}(\mathrm{X}, \mathrm{Y}, \text { weight) where: - } \\
\text { - }(\mathrm{X}, \mathrm{Y}) \text { : represent the } \\
\text { Dung's argumentation } \\
\text { framework. } \\
\text { - weight: represent this } \\
\text { relation }(\mathrm{Y} \rightarrow \mathbb{R}>) \text { is a } \\
\text { function assigning real } \\
\text { valued weights argu- } \\
\text { ments attacks. }\end{array}$ & $\begin{array}{l}\text { The main idea of this } \\
\text { framework is that it ex- } \\
\text { tends the Dung's frame- } \\
\text { work by add new element } \\
\text { called weight it very } \\
\text { important to determine the } \\
\text { winner from several argu- } \\
\text { ments that attacked be- } \\
\text { tween each other. }\end{array}$ & $\begin{array}{l}\text { - Artificial intelli- } \\
\text { gence. } \\
\text { - Decision making. } \\
\text { - Applications with } \\
\text { conflict. } \\
\text { - Expert systems. }\end{array}$ \\
\hline 9 & $\begin{array}{l}\text { Bayesian Argumen- } \\
\text { tation Framework }\end{array}$ & $\begin{array}{l}((\mathrm{X}, \mathrm{Y}, \mathrm{Z}), \text { where - } \\
\text { - X: represent the evi- }\end{array}$ & $\begin{array}{l}\text { The main idea of the BAF } \\
\text { is that it gives a conflict }\end{array}$ & $\begin{array}{l}\text { - Artificial intelli- } \\
\text { gence. }\end{array}$ \\
\hline
\end{tabular}




\begin{tabular}{|c|c|c|c|c|}
\hline & (BAF) & $\begin{array}{l}\text { dence tuple of argu- } \\
\text { ments. } \\
\text { Y: represent the assump- } \\
\text { tion tuple of arguments. } \\
\text { - Z: represent the proposal } \\
\text { tuple of arguments. }\end{array}$ & $\begin{array}{l}\text { resolution mechanism and } \\
\text { the diagnosis of errors, } \\
\text { depending on the argumen- } \\
\text { tation system. }\end{array}$ & $\begin{array}{l}\text { - Decision making. } \\
\text { - Applications with } \\
\text { conflict. } \\
\text { - Expert systems. }\end{array}$ \\
\hline 10 & $\begin{array}{l}\text { Partial argumenta- } \\
\text { tion system (PAF) }\end{array}$ & $\begin{array}{l}\text { (X, Relation, } \mathrm{Y}, \mathrm{Z}) \text { where - } \\
\text { - } \mathrm{X} \text { : represents the finite } \\
\text { tuple of arguments. } \\
\mathrm{R}, \mathrm{Y}, \mathrm{Z} \text { are binary rela- } \\
\text { tions on } \mathrm{X} \text { - } \\
\text { - } \mathrm{R} \text { : represents the attack } \\
\text { relation. } \\
\text { - } \mathrm{Y} \text { : represents element } \\
\text { called the ignorance re- } \\
\text { lation and is such that } \\
\text { Relation } \cap \mathrm{Y}=\emptyset \text {. } \\
\mathrm{Z}: \text { is represented by } \mathrm{Z}= \\
(\mathrm{X} \times \mathrm{X}) \text {. }\end{array}$ & $\begin{array}{l}\text { The main idea to the PAF } \\
\text { is that it is extends Dung's } \\
\text { argumentation system to } \\
\text { represent ignorance con- } \\
\text { cerning the attack relation } \\
\text { and depend on the voting } \\
\text { system to determine that } \\
\text { issue. }\end{array}$ & $\begin{array}{l}\text { - Artificial intelli- } \\
\text { gence. } \\
\text { - Decision making. } \\
\text { - Applications with } \\
\text { conflict. } \\
\text { - Expert systems. }\end{array}$ \\
\hline 11 & $\begin{array}{l}\text { deontic argumenta- } \\
\text { tion frameworks } \\
\text { (DAF) }\end{array}$ & \begin{tabular}{|l|} 
Where - \\
the plain literal state- \\
ment represented the \\
atomic proposition p or \\
the negation of an atom- \\
ic proposition, i.e., $\neg$ p, \\
and \\
the deontic literal state- \\
ment is a statement of \\
the form Og or $\neg \mathrm{Og}$ \\
such that g is a plain \\
literal statement.
\end{tabular} & $\begin{array}{l}\text { The main idea of this } \\
\text { framework is its focus on } \\
\text { basic concepts in deontic } \\
\text { reasoning, namely obliga- } \\
\text { tions, prohibitions, and } \\
\text { permissions. }\end{array}$ & $\begin{array}{l}\text { - Artificial intelli- } \\
\text { gence. } \\
\text { - Decision making. } \\
\text { - Applications with } \\
\text { conflict. } \\
\text { - Expert systems. }\end{array}$ \\
\hline 12 & $\begin{array}{l}\text { Probabilistic Argu- } \\
\text { mentation Frame- } \\
\text { work (PAF) }\end{array}$ & $\begin{array}{l}\text { (X, Y), where - } \\
\text { - X: represented by } \mathrm{X}= \\
\text { (Args, Att) the argumen- } \\
\text { tation framework. } \\
\text { - Y: } 2 \text { Args } \rightarrow[0 ; 1] \text { is a } \\
\text { probability distribution } \\
\text { over sets of arguments. }\end{array}$ & $\begin{array}{l}\text { The main idea of this } \\
\text { framework is determining } \\
\text { the uncertainty and active } \\
\text { argumentation by using } \\
\text { probabilistic reasoning. }\end{array}$ & $\begin{array}{l}\text { - Artificial intelli- } \\
\text { gence. } \\
\text { - Decision making. } \\
\text { - Applications with } \\
\text { conflict. } \\
\text { - Expert systems. }\end{array}$ \\
\hline 13 & $\begin{array}{l}\text { Probabilistic deontic } \\
\text { argumentation } \\
\text { framework (PDAF) }\end{array}$ & $\begin{array}{l}\text { Mixed between probabilis- } \\
\text { tic and deontic frameworks } \\
\text { elements }\end{array}$ & $\begin{array}{l}\text { The main idea to this frame } \\
\text { is making mixed between } \\
\text { the Probabilistic and } \\
\text { deontic argumentation } \\
\text { frameworks by take an } \\
\text { advantage from above } \\
\text { frameworks. }\end{array}$ & $\begin{array}{l}\text { - Artificial intelli- } \\
\text { gence. } \\
\text { - Decision making. } \\
\text { - Applications with } \\
\text { conflict. } \\
\text { - Expert systems. }\end{array}$ \\
\hline
\end{tabular}

\subsection{Dung's argumentation frameworks (AF)}

Dung in 1995 proposed a theoretical structure for argumentation which centers around the meaning of the situation with arguments. For that reason, it tends to be expected that many arguments are given, just as the various struggles among them. An argument is only an entity in an independent case. But if it is compared to the other arguments here, then its role and effect on the rest of the arguments are highlighted [21, 31]. Also, he showed that it is feasible to break down the worthiness of 
arguments in a theoretical manner, independent of where the arguments come from and how they are created. Additionally, the fundamental thought of this structure addresses various kinds of nonmonotonic methodologies in a uniform setting and decides if the arguments are acceptable or not acceptable. To this end, he presented a shockingly basic idea called abstract argumentation framework to do those things [12, 21]. Now, briefly recall the abstract framework and its component and how it works to fulfill its intended purpose:

Definition 1. The argumentation framework (AF) is a pair of tuples AF $=(\mathrm{arg}$, att) Where: -

- The first one is (arg): it represents a set of arguments.

- The second one is (att): it represents a binary relation on arg.

Attacks $\arg \times \arg$. For two arguments $\mathrm{X}$ and $\mathrm{Y}$, that means the attacks $(\mathrm{X}, \mathrm{Y})$ that is when $(\mathrm{X})$ argument goes to attack the $(\mathrm{Y})$ argument [21] In Dung's argumentation framework, the adequacy of an argument relies upon its enrollment of certain sets, called adequate sets or extensions. These extensions or acceptable augmentations are portrayed by specific properties. It is an aggregate worthiness. The fundamental properties with different types are as follows:

- Conflict-free: where the tuple $\mathrm{Z}$ is subset from tuple $\mathrm{X}$ is conflict-free iff there exist no $\mathrm{Xi}, \mathrm{Xj}$ in $\mathrm{S}$ such that $\mathrm{Xi} \operatorname{Rdef} \mathrm{Xj}$.

- Defends collectively: where the tuple $Z$ is subset from tuple $X$ defends collectively an argument $\mathrm{Xi}$ iff for each argument $\mathrm{y}$, if $\mathrm{Y}$ Rdef xi there exists $\mathrm{C}$ in $\mathrm{Z}$ such that CRdefY.

At that point a few semantics for acceptable arguments have been several characteristic as following: -

Let (X, Rdef) be an argumentation framework.

- Admissible: where the tuple $\mathrm{Z}$ is subset from tuple $\mathrm{X}$ is an admissible set iff $\mathrm{Z}$ is conflict-free and $Z$ protects aggregately the entirety of its components.

- Preferred: where the tuple $Z$ is subset from tuple $X$ is a preferred extension of (X, Rdef) iff $Z$ is maximal for the set consideration among the admissible sets of $X$.

- Stable: where the tuple $Z$ is subset from tuple $X$ is a stable extension of (X, Rdef) iff $\mathrm{S}$ is conflict-free and $\mathrm{Z}$ defeats every argument which does not have a place for $\mathrm{Z}$.

- Grounded: where the tuple $\mathrm{Z}$ is subset from tuple $\mathrm{X}$ is the grounded extension of (X, Rdef) iff $S$ is the least fixed point of the characteristic function of (X, Rdef) (F: $2(X, R d e f) \rightarrow 2(X, R d e f)$ with $F(Z)=\{X$ such that $Z$ defends collectively $X\})$ [21]. 


\subsection{Preferences based argumentation frameworks (PAFs)}

Here is a review dealing with the acceptability of arguments in (PAFs). It gives many contributions to ensure using of these preferences is allowed. Defining defense and joint defense that take place between the various arguments: -

- identify two integral ideas of adequacy (singular agreeableness and joint worthiness) and to introduce a bound together broad system where the two thoughts are utilized.

- consider inclination relations between arguments to choose the most satisfactory of them.

The main idea of this framework is that it extends Dung's framework to three elements. These elements represent the condition that determines the acceptability of the argument $[32,33]$.

Definition 2. The preference-based argumentation framework (PAF) is three tuples (X, Y, Pref) where: -

- $\mathrm{X}$ represents the set of arguments.

- Y represents the binary relation addressing the loss connection where arguments $\mathrm{Y}$ $\subseteq \mathrm{X} \times \mathrm{X}$.

- Pref is a (partial or all) preordering on $\mathrm{X} \times \mathrm{X}$.

This preference-based argumentation framework given by $P F=(A, R, \geq)$ where argumentation framework.

$$
\mathrm{F}=(\mathrm{X}, \mathrm{Y} 1) \text { where } \mathrm{Y} 1=\mathrm{Y} /\{(\mathrm{a}, \mathrm{b}) \mid \mathrm{b}>\mathrm{a}\} .
$$

\subsection{Value based argumentation frameworks (VAFs)}

The fundamental plan is to the value-based argumentation frameworks. It is based on providing a logical environment in which to make a comparison between the arguments that play the role of the attack and those that defend, by creating a basic discussion framework in which to put values of the arguments and work to develop values for those arguments $[9,34,35]$.

Definition 3. The value-based argumentation framework (VAF) has five elements represented by five sets (arguments, attacks, values, Val, P) where: -

- AR: represents the finite tuple that include arguments.

- Attacks: represents the non-reflexive binary relation on tuple AR.

- values: represents the nonempty tuple of values.

- Val: represents the function which maps from elements of tuple AR to elements of tuple values.

- P: represents the tuple of possible audiences. 


\subsection{Extended argumentation framework (EAF)}

In the extended argumentation framework, preferred arguments are not obtained through external orders but are obtained intuitively through arguments that irritate each other like when argument (A) attack on argument (B). At that point one would reason argument (A) defeats argument (B) if the arguments $S$ that one is right now dedicated to, contain no argument guaranteeing that B is liked to A. In other words, the accomplishment of an attack as a loss, the inclination arguments accessible in whatever set $\mathrm{S}$ of argument. The primary thought for (EAF) it not exclusively to attack different arguments yet additionally different attacks and in same time permit to the argument to create a further developed clash connection [36, 37].

Definition 4. An Extended Argumentation Framework (EAF) has three sets (arguments, $\mathrm{X}, \mathrm{Y}$ ) where: -

- arguments represent the tuple of arguments.

- $\mathrm{X} \subseteq$ arguments $\times$ arguments.

- $\mathrm{Y} \subseteq$ arguments $\times \mathrm{X}$.

\subsection{Bipolar argumentation framework (BAF)}

An abstract bipolar argumentation framework is an expansion the argumentation framework structure presented Dung [21] depend on the communication between arguments addressed by the supporting connection. This new connection is thought to be free of the loss connection (like it is not characterized utilizing the loss connection). Thus, this framework has a bipolar portrayal of the associations between arguments. A bipolar argumentation structure can in any case be addressed by a coordinated diagram, with two sorts of edges, one for the loss connection and another for the support connection. In another term the primary plan to the BAF it provides tuple of relationship rout connection and supporting connection [26, 38, 39, 40].

Definition 5. The abstract bipolar argumentation framework includes three elements (X, Ydef, Ysup) where -

- $X$ : represent the tuple of arguments.

- Ydef: represent the binary relation Ydef on tuple $\mathrm{X}$ that is represent the defeat relation.

- Ysup: represent the binary relation Rsup on tuple $\mathrm{X}$ that is represent the support relation.

\subsection{Abstract dialectical frameworks (ADFs)}

The abstract dialectical frameworks (ADFs), the Brewka and Woltran give this framework by developing the argumentation framework that is introduced by Dung and provide new argumentation systems. The main idea is to establish a specific acceptance condition for arguments that allows for abstract arguments as well as for flexible and abstract relationships. More officially, a theoretical persuasive structure is a coordinated chart whose hubs address arguments, the statements or positions 
which can be acknowledged or not. All in all, the principle thought to the ADF it adding to every argument a particular acknowledgment condition [1].

Definition 6. The abstract dialectical framework is a set $R=(X, Y, Z)$ where: -

- $\mathrm{X}$ : represent the tuple statements (positions, nodes).

- $\mathrm{Y}$ : represented by $\mathrm{Y} \subseteq \mathrm{X} \times \mathrm{X}$ is a tuple of links.

- $\mathrm{Z}$ : represented by $\mathrm{Z}=\{\mathrm{Zx}\} \mathrm{x} \in \mathrm{X}$ is a tuple of total functions.

\subsection{Control argumentation frameworks (CAFs)}

It sums up the strategies, in particular the typical augmentation requirement, by obliging the chance of vulnerability in unique situations. The part (A) in the CAF can manage circumstances where the specific arrangement of arguments is obscure and dependent upon development, and the presence (or bearing) of certain attacks is additionally obscure. It very well may be utilized by a specialist to guarantee that several arguments are important for one (or each) augmentation whatever the genuine arrangement of arguments and attacks, the CAF incorporate three sections the initial segment called part (F) is the fixed piece of the CAF. This piece of the framework which cannot be affected either by the specialist or by the climate. The subsequent part called $U$ it addresses the potential changes of the climate and the setting subordinate data. This can be viewed as dangers against an objective identified with the fixed part. The third part in this framework called (C) it addresses all that which can be chosen by the specialist, this part is viewed as the therapeutic activities to ensure the objective. At last, the principle thought to the CAF is that it gives a dynamic model; it can change over the long run mirroring the elements of the climate [41].

Definition 7. Let (Lang) be a language from which the system can build arguments and for example arguments (Lang) represent the tuple which contains all those arguments.

The Control Argumentation Framework includes three elements $\mathrm{CAF}=(\mathrm{X}, \mathrm{Y}, \mathrm{Z})$ where:

- $\mathrm{X}$ : this element represents the fixed part in the framework.

- $Y$ : this element represents the uncertain part in the framework.

- $\mathrm{Z}$ : this element represents the control part in the framework.

\subsection{Weighted argument framework (WAF)}

A characteristic argumentation of Dung's argumentation framework is that in this system the argument is linked to a weight that represents its size and indicates the relative strength of the attack this system is based on the concept of budget inconsistency. The characteristic of the inconsistency is its adaptation to be hampered by an inconsistent budget $(\beta)$ where attacks with a total weight of inconsistency $(\beta)$ are ignored. The vital benefit of this methodology is that it allows a lot better grained level of examination of argument frameworks than unweighted frameworks and gives valuable arrangements when customary (unweighted) argument frameworks have 
none. This model starts by looking into Dung's theoretical argument frameworks and rousing loads on attacks (instead of the elective chance, which is to connect loads to arguments). This system does not depend on how or how the weight is found rather, it relies on the weighted arguments themselves and it focuses on the difference in those weights to reach the result of the dialectic. The primary thought of this structure it expands the fertilizer's system by add new component called weight it vital to decide the champ from a few arguments that attacked between one another [42] [43].

Definition 8. The weighted argument framework represented by three elements $\mathrm{WAF}=(\mathrm{X}, \mathrm{Y}$, weight $)$ where: -

- $(\mathrm{X}, \mathrm{Y})$ : represent the Dung's argumentation framework.

- weight: represent this relation $(Y \rightarrow \mathbb{R}>$ ) is a function assigning real valued weights arguments attacks.

Notice this framework works with non-zero weight to each argument that thing is very necessary. This is because arguments of zero weight can be easily overcome by competitors, as their presence and absence are not considered a valuable thing, and therefore they are discarded as a foregone conclusion.

\subsection{Bayesian argumentation framework (BAF)}

The Bayesian argumentation framework utilizes the (Causal Model) to work and it depends on the possibility of probabilistic explanations assembled that is extracted from the input argument. It uses this model because it made from several factors and their restrictive probabilistic conditions, as clarified assembled into several articulations to adjust arguments. In view of the three sorts of explanations, this system defines three types of statements: the first statement represents the set for certain data; the second statement represents the set for questionable data; the third statement represents the remaining one for proposing ends or explanations. The fundamental plan to the BAF gives a compromise component and the conclusion of blunders, contingent upon the argumentation framework [44, 45].

Definition 9. The Bayesian Argumentation Framework includes three elements each element represents the set of arguments (X, Y, Z), where: -

- $\mathrm{X}$ : represent the evidence tuple of arguments.

- Y: represent the assumption tuple of arguments.

- Z: represent the proposal tuple of arguments.

\subsection{Partial argumentation system (PAF)}

The hidden argumentation hypothesis is Dung's argumentation framework. Every argumentation framework gives both several arguments and the way they associate (i.e., attack or non-attack) as indicated by the comparing specialist. The insufficiency of the straightforward, yet engaging, way which comprises in deciding on the specialists' chosen expansions requires another technique. For this reason, an overall structure for consolidating argumentation frameworks from Dung's argumentation frame- 
work system is introduced. There are three stages to this framework which achieved the first stage and expend each argument into partial system by using tuple of arguments depend on number of agents. (Some agents may ignore some of the arguments while others rely on them and so forth). The second stage conflict possibilities are resolved by using merge where a set of systems for discussion is fully established the third stage is voting by depended on agents [46].

Definition 10. The partial argumentation system $X$ (finite) partial argumentation system over $\mathrm{X}$ is a four tuples PAF $=(\mathrm{X}$, Relation, $\mathrm{Y}, \mathrm{Z})$ where: -

- X: represents the finite tuple of arguments.

$\mathrm{R}, \mathrm{Y}, \mathrm{Z}$ are binary relations on $\mathrm{X}$ : -

- R: represents the attack relation.

- Y: represents an element called the ignorance relation and is such that Relation $\cap$ $\mathrm{Y}=\varnothing$.

- $Z$ : represented by $Z=(X \times X)$.

\subsection{Deontic argumentation frameworks (DAF)}

Legal and deontic reasoning expose varied concepts ranging from basic obligations and permissions to liberties and rights. For our purposes, the main idea of this framework its focus on basic concepts in deontic reasoning, namely obligations, prohibitions, and permissions. Obligations are the essence of this system, and the provisions are a by-product of these obligations where the opposite thing is forbidden, and vice versa. Permissions can be understood in terms of obligations too: a permission for something expresses that the opposite is not obligatory. Accordingly, and for the sake of simplicity, the attention is restricted to a propositional language which is supplemented with a single deontic operator $\mathrm{O}$ which indicates an obligation [47].

Definition 11. The statement of literal to the language LD represented the plain literal statement or a deontic literal statement where:

- The plain literal statement represented the atomic proposition $p$ or the negation of an atomic proposition, i.e., $\neg$ p, and.

- The deontic literal statement is a statement of the form $\mathrm{Og}$ or $\neg \mathrm{Og}$ such that $\mathrm{g}$ is a plain literal statement.

The concept permissions and concept prohibitions are captured by assuming that a prohibition Fg is equivalently expressed by the obligation $\mathrm{O} \overline{\mathrm{g}}$, and a permission $\mathrm{Pg}$ is syntactically equivalent to $\neg \mathrm{O} \overline{\mathrm{g}}$.

\subsection{Probabilistic argumentation framework (PAF)}

Now think about a probabilistic speculation of these ideas. Given a structure (Args Att), the primary thought of this system is deciding the vulnerability and dynamic 
argumentation by utilizing probabilistic, there might be vulnerability about whether an argument $\mathrm{a} \in$ Args is dynamic. This vulnerability may emerge, for instance, from -

- Uncertainty of proof. Singular bits of proof, on which an argument is based, might be dubious. This vulnerability extends to the argument. So, the likelihood that the argument is dynamic is the likelihood that the proof is valid.

- Opponent displaying. On the off chance that can utilize a system to demonstrate the information on an adversary (like the setting of an argumentation game), might be dubious about which arguments the rival knows about. So, the likelihood that the argument is dynamic is the likelihood that the rival knows about the argument $[5,48]$.

To address this sort of vulnerability, present the idea of a probabilistic system -

Definition 12. The probabilistic framework includes two elements $P F=(X, Y)$, where -

- $X$ : represented by $X=($ Args, Att) the argumentation framework.

- Y: $2 \operatorname{Args} \rightarrow[0 ; 1]$ is a probability distribution over sets of arguments.

\subsection{Probabilistic deontic argumentation framework (PDAF)}

Given several standards and a situation displayed as a defeasible hypothesis, this framework allows us to link the acceptances of the due form and the related violations and evaluates the probability in an initial way. To achieve this, this system integrates due arguments and reformulates the due principles as well [49] so it is the probabilistic approach of grandiose such that the value of an argument is related to its name [50]. By embodying the principle of prohibition, the processing is done to fulfill the standard Then you combine the prescriptive combination with the probabilistic that has the character of the probabilistic argument this allows the probability values to be linked to acceptances. The main idea to this frame is making a mixture of the probabilistic and deontic argumentation frameworks by take an advantage from the above frameworks [5].

\section{Conclusion}

This paper portrayed the field of theoretical argumentation and gave an outline of the as of now accessible structures that broaden Dung's underlying framework by joining inclinations and relations beyond attack. It also focuses on the main idea of each framework. Dung gives two tuples that represent the input arguments and relation attack between them [21]. The Preferences-Based Argumentation Frameworks (PAFs) focus on the acceptability by make a process and give conditions to determine the preferences arguments [32]. Value-Based Argumentation Frameworks (VAFs) provide a rational basis for the acceptance or rejection of arguments by making comparison between the attacked argument and supported arguments and choose between them $[9,34,35]$. The Extended Argumentation Framework (EAF), not only to attack 
other arguments but also on other attacks and same time allow to the argument to generate a more advanced conflict relation [37]. The Bipolar Argumentation Framework (BAF) gives to set of relationship defeat relation and support relation [38]. Abstract dialectical frameworks (ADFs), add to each argument a specific acceptance condition [1]. Control Argumentation Frameworks (CAFs) provide dynamic models that can change over time reflecting the dynamics of the environment [41]. The Weighted Argument Framework (WAF) extends Dung's framework by adding a new element called weight. It very important to determine the winner from several arguments that attacked between each other [42]. The Bayesian Argumentation Framework (BAF) gives a conflict resolution mechanism and the diagnosis of errors, depending on the argumentation system [45]. The Partial Argumentation System (PAF), extends Dung's argumentation system to represent ignorance concerning the attack relation and depends on the voting system to determine that issue [46]. The Deontic Argumentation Frameworks (DAF) focuses on basic concepts in deontic reasoning, namely obligations, prohibitions, and permissions [47]. The Probabilistic Argumentation Framework (PAF) determines the uncertainty and active argumentation by using probabilistic reasoning $[5,48]$. The Probabilistic Deontic Argumentation Framework (PDAF) mixes the Probabilistic and Deontic argumentation frameworks by taking an advantage of the above frameworks [5]. Although all the argumentation frameworks are characterized by the ability to identify acceptable arguments and distinguish them from those that are not acceptable, all methods mentioned above share the same limitation, which is the result of resolving the controversy remains ambiguous in most cases because they give a set of acceptable solutions. In future work we suggest an argumentation framework that gives the result clearly, which would greatly help the decision-making process.

\section{$5 \quad$ References}

[1] G. Brewka and S. Woltran, "Abstract dialectical frameworks,” Proc. Int. Conf. Knowl. Represent. Reason., no. Kr, pp. 102-111, 2010.

[2] A. Hunter, "Elements of argumentation," Lect. Notes Comput. Sci. (including Subser. Lect. Notes Artif. Intell. Lect. Notes Bioinformatics), vol. 4724 LNAI, no. October 2007, p. 4, 2007. https://doi.org/10.1007/978-3-540-75256-1_3

[3] T. J. M. Bench-Capon and P. E. Dunne, "Argumentation in artificial intelligence," Artif. Intell., vol. 171, no. 10-15, pp. 619-641, 2007. https://doi.org/10.1016/j.artint.2007.05.001

[4] L. Amgoud and H. Prade, "Using arguments for making and explaining decisions," Artif. Intell., vol. 173, no. 3-4, pp. 413-436, 2009. https://doi.org/10.1016/j.artint.2008.11.006

[5] R. Riveret, N. Oren, and G. Sartor, "A probabilistic deontic argumentation framework," Int. J. Approx. Reason., vol. 126, pp. 249-271, 2020. https://doi.org/10.1016/j.ijar.2020.08 $\underline{.012}$

[6] A. T. Sadiq, Argumentation in Artificial Intelligence. 2019.

[7] N. Gorogiannis and A. Hunter, "Instantiating abstract argumentation with classical logic arguments: Postulates and properties,” Artif. Intell., vol. 175, no. 9-10, pp. 1479-1497, 2011. https://doi.org/10.1016/j.artint.2010.12.003 
[8] A. Bondarenko, P. M. Dung, R. A. Kowalski, and F. Toni, "Artificial Intelligence An abstract, argumentation-theoretic approach to default reasoning," Artif. Intell., vol. 93, no. 97, pp. 63-101, 1997. https://doi.org/10.1016/s0004-3702(97)00015-5

[9] S. Modgil and T. J. M. Bench-Capon, "Metalevel argumentation,” J. Log. Comput., vol. 21, no. 6, pp. 959-1003, 2011. https://doi.org/10.1093/logcom/exq054

[10] I. Rahwan and G. R. Simari, "Argumentation in artificial intelligence," Argumentation Artif. Intell., pp. 1-493, 2009. https://doi.org/10.1007/978-0-387-98197-0

[11] P. Torroni, L. Van Der Torre, S. W. Eds, I. Workshop, C. Xiv, and R. Goebel, in MultiAgent Systems, no. September. 2013.

[12] G. Brewka, S. Polberg, and S. Woltran, "Generalizations of dung frameworks and their role in formal argumentation,” IEEE Intell. Syst., vol. 29, no. 1, pp. 30-38, 2014. https://do i.org/10.1109/MIS.2013.122

[13] D. Cartwright and K. Atkinson, "Using computational argumentation to support eparticipation,” IEEE Intell. Syst., vol. 24, no. 5, pp. 42-52, 2009. https://doi.org/10.1109/ MIS.2009.104

[14] K. Atkinson et al., "Toward artificial argumentation," AI Mag., vol. 38, no. 3, pp. 25-36, 2017. https://doi.org/10.1609/aimag.v38i3.2704

[15] K. Jasim, A. T. Sadiq, and H. S. Abdullah, "A Framework for Detection and zdentification the Components of Arguments in Arabic Legal Texts," 1st Int. Sci. Conf. Comput. Appl. Sci. CAS 2019, pp. 67-72, 2019. https://doi.org/10.1109/CAS47993.2019.9075650

[16] T. J. M. Bench-Capon, "Before and after Dung: Argumentation in AI and Law," Argument Comput., vol. 11, no. 1-2, pp. 221-238, 2020. https://doi.org/10.3233/aac-190477

[17] N. Gulati and P. D. Kaur, "A game theoretic approach for conflict resolution in argumentation enabled social IoT networks," Ad Hoc Networks, vol. 107, p. 102222, 2020. https://do i.org/10.1016/j.adhoc.2020.102222

[18] P. A. Matt and F. Toni, "A game-theoretic measure of argument strength for abstract argumentation," Lect. Notes Comput. Sci. (including Subser. Lect. Notes Artif. Intell. Lect. Notes Bioinformatics), vol. 5293 LNAI, pp. 285-297, 2008. http://dx.doi.org/10.1007/9783-540-87803-2 24

[19] H. Prakken, "Coherence and flexibility in dialogue games for argumentation," J. Log. Comput., vol. 15, no. 6, pp. 1009-1040, 2005. https://doi.org/10.1093/logcom/exi046

[20] S. Bistarelli and F. Santini, "An introduction to optimal stable marriage problems and argumentation frameworks,” CEUR Workshop Proc., vol. 2528, pp. 80-84, 2019.

[21] P. M. Dung, "On the acceptability of arguments and its fundamental role in nonmonotonic reasoning, logic programming and n-person games," Artif. Intell., vol. 77, no. 2, pp. 321357, 1995. https://doi.org/10.1016/0004-3702(94)00041-X

[22] J. Fox et al., "Delivering clinical decision support services: There is nothing as practical as a good theory," J. Biomed. Inform., vol. 43, no. 5, pp. 831-843, 2010. https://doi.org/10.10 16/i.jbi.2010.06.002

[23] A. Hunter and M. Williams, "Aggregating evidence about the positive and negative effects of treatments," Artif. Intell. Med., vol. 56, no. 3, pp. 173-190, 2012. https://doi.org/10.101 6/j.artmed.2012.09.004

[24] K. Atkinson, T. Bench-Capon, and P. McBurney, "PARMENIDES: Facilitating deliberation in democracies," Artif. Intell. Law, vol. 14, no. 4, pp. 261-275, 2006. https://doi.org/1 0.1007/s10506-006-9001-5

[25] G. Boella, D. M. Gabbay, L. Van Der Torre, and S. Villata, "Support in abstract argumentation," Front. Artif. Intell. Appl., vol. 216, pp. 111-122, 2010. https://doi.org/10.1007/s10 472-012-9317-7 
[26] A. Cohen, S. Gottifredi, A. J. García, and G. R. Simari, "A survey of different approaches to support in argumentation systems," Knowl. Eng. Rev., vol. 29, no. 5, pp. 513-550, 2013. https://doi.org/10.1017/S0269888913000325

[27] C. Cayrol and M. C. Lagasquie-Schiex, "Bipolarity in argumentation graphs: Towards a better understanding," Int. J. Approx. Reason., vol. 54, no. 7, pp. 876-899, 2013. https://do i.org/10.1016/j.ijar.2013.03.001

[28] P. Baroni and M. Giacomin, "On principle-based evaluation of extension-based argumentation semantics," Artif. Intell., vol. 171, no. 10-15, pp. 675-700, 2007. https://doi.org/10. 1016/j.artint.2007.04.004

[29] T. Alsinet, J. Argelich, R. Béjar, C. Fernández, C. Mateu, and J. Planes, "Weighted argumentation for analysis of discussions in Twitter," Int. J. Approx. Reason., vol. 85, pp. 2135, 2017. https://doi.org/10.1016/j.ijar.2017.02.004

[30] J. Sohn et al., "Argumentation corrected context weighting-life cycle assessment: A practical method of including stakeholder perspectives in multi-criteria decision support for LCA," Sustain., vol. 12, no. 6, 2020. https://doi.org/10.3390/su12062170

[31] S. Bistarelli and F. Santini, "ConArg: A constraint-based computational framework for argumentation systems," Proc. - Int. Conf. Tools with Artif. Intell. ICTAI, pp. 605-612, 2011. https://doi.org/10.1109/ICTAI.2011.96

[32] L. Amgoud and C. Cayrol, "A reasoning model based on the production of acceptable arguments,” Ann. Math. Artif. Intell., vol. 34, no. 1-3, pp. 197-215, 2002. https://doi.org/10. 1023/A:1014490210693

[33] L. Amgoud and S. Vesic, "A new approach for preference-based argumentation frameworks,” Ann. Math. Artif. Intell., vol. 63, no. 2, pp. 149-183, 2011. https://doi.org/10.1007 /s10472-011-9271-9

[34] T. J. M. Bench-Capon, "Persuasion in practical argument using value-based argumentation frameworks,” J. Log. Comput., vol. 13, no. 3, pp. 429-448, 2003. https://doi.org/10.1093/1 ogcom/13.3.429

[35] C. Reed, "Agreeing to Differ: Modelling Persuasive Dialogue Between Parties With Different Values," Informal Log., vol. 22, no. 3, 2001. https://doi.org/10.22329/il.v22i3.2590

[36] T. Bench-Capon and S. Modgil, "Norms and extended argumentation frameworks," Proc. 17th Int. Conf. Artif. Intell. Law, ICAIL 2019, pp. 174-178, 2019. https://doi.org/10.1145/ 3322640.3326696

[37] S. Modgil, "Reasoning about preferences in argumentation frameworks," Artif. Intell., vol. 173, no. 9-10, pp. 901-934, 2009. https://doi.org/10.1016/j.artint.2009.02.001

[38] C. Cayrol and M. C. Lagasquie-Schiex, "On the acceptability of arguments in bipolar argumentation frameworks," Lect. Notes Comput. Sci. (including Subser. Lect. Notes Artif. Intell. Lect. Notes Bioinformatics), vol. 3571 LNAI, pp. 378-389, 2005. https://doi.org/10. $1007 / 1151865533$

[39] F. Nouioua and V. Risch, "Bipolar argumentation frameworks with specialized supports," Proc. - Int. Conf. Tools with Artif. Intell. ICTAI, vol. 1, pp. 215-218, 2010. https://doi.org/ $\underline{10.1109 / \text { ICTAI.2010.37 }}$

[40] G. De Tre, A. Hallez, and A. Bronselaer, "Performance optimization of object comparison,” Int. J. Intell. Syst., vol. 29, no. 2, pp. 495-524, 2014. https://doi.org/10.1002/int.2268 $\underline{9}$

[41] Y. Dimopoulos, J. G. Mailly, and P. Moraitis, "Control argumentation frameworks," 32nd AAAI Conf. Artif. Intell. AAAI 2018, no. Pulina 2016, pp. 4678-4685, 2018.

[42] P. E. Dunne, A. Hunter, P. McBurney, S. Parsons, and M. Wooldridge, "Weighted argument systems: Basic definitions, algorithms, and complexity results," Artif. Intell., vol. 175, no. 2, pp. 457-486, 2011. https://doi.org/10.1016/j.artint.2010.09.005 
[43] P. E. Dunne, S. Parsons, A. Hunter, P. McBurney, and M. Wooldridge, "Inconsistency tolerance in weighted argument systems," Proc. Int. Jt. Conf. Auton. Agents Multiagent Syst. AAMAS, vol. 1, no. Aamas, pp. 616-623, 2009.

[44] A. H. Hong and F. R. Sullivan, "Towards an idea-centered, principle-base design to as creation approach support learning knowledge,” Educ. Technol. Res. Dev., vol. 57, no. 5, pp. 613-627, 2013. https://doi.org/10.1007/s11423-009-9122-0

[45] Á. Carrera, E. Alonso, and C. A. Iglesias, "A bayesian argumentation framework for distributed fault diagnosis in telecommunication networks," Sensors (Switzerland), vol. 19, no. 15, 2019. https://doi.org/10.3390/s19153408

[46] S. Coste-Marquis, C. Devred, S. Konieczny, M. C. Lagasquie-Schiex, and P. Marquis, "On the merging of Dung's argumentation systems," Artif. Intell., vol. 171, no. 10-15, pp. 730-753, 2007. https://doi.org/10.1016/j.artint.2007.04.012

[47] R. Urbaniak, Probabilistic legal decision standards still fail. .

[48] T. Rienstra, "Towards a probabilistic Dung-style argumentation system," CEUR Workshop Proc., vol. 918, no. October, pp. 138-152, 2012.

[49] G. Pigozzi and L. van der Torre, "Arguing about constitutive and regulative norms," J. Appl. Non-Classical Logics, vol. 28, no. 2-3, pp. 189-217, 2018. https://doi.org/10.1080/1 1663081.2018 .1487242

[50] R. Riveret, P. Baroni, Y. Gao, G. Governatori, A. Rotolo, and G. Sartor, A labelling framework for probabilistic argumentation, vol. 83, no. 1. 2018. https://doi.org/10.1007/s1 0472-018-9574-1

\section{Authors}

Ahmed T. Sadiq is with Computer Sciences Department, University of Technology, Baghdad, Iraq.

Hasanen S. Abdulah is with Computer Sciences Department, University of Technology, Baghdad, Iraq.

Adnan Taher Kareem is with Iraqi Ministry of Communications, Baghdad, Iraq.

Article submitted 2021-11-03. Resubmitted 2021-12-18. Final acceptance 2021-12-19. Final version published as submitted by the authors. 